\title{
Clinical follow-up and breast and ovarian cancer screening of true BRCA1/2 noncarriers: a qualitative investigation
}

\author{
Sylvie Pelletier', Nora Wong², Zaki El Haffaf ${ }^{3}$, William D. Foulkes $2,4,5$, \\ Jocelyne Chiquette ${ }^{1,6}$, Pavel Hamet ${ }^{7}$, Jacques Simard ${ }^{1,8}$, and Michel Dorval ${ }^{1,6,9}$
}

\begin{abstract}
Purpose: Most women from $B R C A 1 / 2$ mutation-positive families who did not inherit the familial mutation have breast and ovarian cancer risks similar to those of women of the same age in the general population. However, recent studies suggest that some of these noncarriers may exhibit screening practices that may be considered as excessive compared to general population screening guidelines. Reasons for such tendencies remain largely unknown. This study aims to better understand how the implications of a noncarrier status are explained to these women and how their own realization of this status affects their screening behaviors.
\end{abstract}

Methods: A qualitative study was conducted with five focus groups $(n=28)$ in Quebec City and Montreal, Canada.

Results: Thematic analysis of the discussions highlighted four major themes: (i) acquiring a noncarrier identity takes place progressively; (ii) noncarriers show a range of opinions about screening; (iii) noncarriers have mixed feelings about the followup by their physicians and gynecologists; and (iv) noncarriers need more information in a context where genetics progresses ever more rapidly.

Conclusion: Our results provide novel insights regarding the physician-patient interaction and the organizational aspects of the health-care system that may significantly impact the cancer screening practices of $B R C A 1 / 2$ noncarriers.

Genet Med advance online publication 5 November 2015

Key Words: BRCA1/2 genes; cancer screening; noncarriers; patientphysician interaction; qualitative research

\section{INTRODUCTION}

$B R C A 1$ and BRCA2 mutations are estimated to increase a woman's lifetime risk for development of breast cancer and ovarian cancer by up to 85 and $50 \%$, respectively. ${ }^{1}$ However, in the absence of other significant risk factors, women belonging to $B R C A 1 / 2$ mutation-positive families but who do not carry the familial mutation (i.e., true noncarriers) are estimated to have near-population breast and ovarian cancer risks ${ }^{2,3}$ and are generally considered to dispense with any specialized genetic followup. ${ }^{3,4}$ They are then referred back to their primary-care doctors, who should encourage them to adopt the cancer screening practices recommended for women of the same age in the general population. ${ }^{3,5,6}$ In Canada, the most recent of these recommendations apply only to women aged 50 to 74 years, who should undergo a mammography every $2-3$ years. ${ }^{7}$ Since 2001, mammography may also be prescribed to women aged $40-49$, particularly those with a family history of cancer, after discussing the risks and benefits of the examination with their physician. Breast self-examination, breast ultrasound, breast magnetic resonance imaging, pelvic/transvaginal ultrasound, and CA-125 testing are not recommended for breast or ovarian cancer screening. ${ }^{7-9}$
True noncarriers are not expected to extensively use breast or ovarian cancer screening examinations., ${ }^{3,10}$ However, some studies have recently reported "excessive" screening behaviors among this population. ${ }^{11-13}$ Attempts to explain these behaviors ${ }^{11-14}$ so far have mainly been directed to possible associations with noncarriers' characteristics. Despite a recent upsurge in research on this particular subgroup, ${ }^{11,13-16}$ true $B R C A 1 / 2$ noncarriers still remain relatively understudied, and current knowledge about screening behaviors and potentially associated factors in this population is limited.

We conducted a qualitative study that aimed to gain insight into the experience of being a true $B R C A 1 / 2$ noncarrier and how this experience actually affects screening behaviors, and especially why it may contribute in some cases to cancer screening practices that are noncompliant with regard to the recommendations for this population. The study also intended to investigate the information needs of noncarriers regarding cancer screening and to outline how health professionals could provide them with complete information about the benefits and risks of screening.

\footnotetext{
${ }^{1}$ Centre de Recherche du CHU de Québec-Université Laval, Quebec City, Quebec, Canada; ${ }^{2}$ Department of Medical Genetics, Jewish General Hospital, Montreal, Quebec, Canada; ${ }^{3}$ Service de Médecine Génique, Centre Hospitalier de l'Université de Montréal (CHUM), Montreal, Quebec, Canada; ${ }^{4}$ Lady Davis Institute of the Jewish General Hospital, Montreal, Quebec, Canada; ${ }^{5}$ Departments of Oncology, Human Genetics and Medicine, McGill University, Montreal, Quebec, Canada; ${ }^{6} \mathrm{Centre}$ des Maladies du Sein Deschênes-Fabia, CHU de Québec, Université Laval, Quebec City, Quebec, Canada; ${ }^{7}$ Centre de Recherche, Centre Hospitalier de l’Université de Montréal (CHUM), Montreal, Quebec, Canada; ${ }^{8}$ Faculté de Médecine, Université Laval, Quebec City, Quebec, Canada; ${ }^{9}$ Faculté de Pharmacie, Université Laval, Quebec City, Quebec, Canada. Correspondence: Michel Dorval (michel.dorval@crchudequebec.ulaval.ca)
} 


\section{MATERIALS AND METHODS}

\section{Design}

A qualitative approach (focus groups) was singled out as the method of choice to achieve our objectives because of its ability to uncover factors potentially associated with complex behaviors and to gain insight into their underlying motivations. ${ }^{17}$

\section{Participants}

Eligible participants were unaffected women from families in which a $B R C A 1 / 2$ mutation had already been identified in at least one member, who had undergone $B R C A 1 / 2$ genetic testing, and whose test result had shown them to be negative (noncarriers) for the familial mutation (i.e., true negatives). They had to be aged between 18 and 69 years at the time of test result disclosure. These women had been tested between 1 January 2002 and 31 December 2011 in four centers where BRCA1/2 genetic counseling and testing are available in the province of Quebec (Canada). Potential participants were informed about this study over the telephone by a research assistant who explained the study and confirmed the woman's eligibility. Minimal contact information (name, language, and telephone number) about the women who had consented to enter the study was then forwarded to a research firm that was contracted to organize and conduct the focus groups. The choice to proceed with an independent firm was based on the researchers' previous experience, which had shown the importance of having group discussions conducted by someone not belonging to the clini$\mathrm{cal} /$ research team to allow participants to talk freely about their experience with their medical follow-up. To form groups that were most representative of the noncarrier population, selection criteria were purposively applied to recruit women from different age groups, with different follow-up duration since test result disclosure, and with various screening experiences.

\section{Focus groups}

Five focus group sessions were held in November and December 2013 in Montreal (4) and Quebec City (1). Four groups were conducted in French and one in English. Group sessions were held similarly in both cities in the research firm's survey facilities, which were equipped with all necessary services. At least two members of the research team observed each group session behind a one-way mirror. M.D. and S.P. observed all groups.

An experienced, bilingual, professional female moderator headed the five group discussions using a semi-structured discussion guide developed by the research team (see Supplementary Material online). The latter guide helps to ensure consistency between the groups and to stay on course with the topics of interest. ${ }^{17}$ Open-ended questions and probes were asked by the moderator as required. Each group discussion lasted $\sim 2$ hours. They were audio- and videorecorded and transcribed verbatim. Field notes were also taken by hidden group observers. Confidentiality was maintained by using first names only. Participants were informed of the study objectives and of the presence of members of the research team observing the discussions behind a one-way mirror. Each participant received compensation of $\$ 60$ (Canadian). This study was approved by the institutional ethics review boards of all participating institutions. All participants signed a consent form before entering the study.

\section{Data analysis}

The content of the group discussions and field notes was analyzed according to established qualitative analysis methodology. ${ }^{18-20}$ Thematic analysis was performed by an experienced coder (S.P.). A combination of inductive and deductive approaches was chosen for the process. The subdivisions of the discussion guide were used as a general coding template, and additional categories and subcategories that emerged were included as coding proceeded, with resulting revisions and modifications of the coding structure. Content units were coded using the NVivo 8 software. ${ }^{21}$

\section{Findings}

Eligible women were approached and informed about the study until seven to nine potential participants per group were accepted. Thirty-five women submitted a signed consent form. These women were then contacted by the research firm and

Table 1 Relevant quotes for theme 1: becoming a noncarrier

\begin{tabular}{|c|c|c|}
\hline Selected subthemes & Quotes & $\begin{array}{l}\text { Age/years since } \\
\text { test disclosure }\end{array}$ \\
\hline $\begin{array}{l}\text { Disbelief concerning } \\
\text { noncarrier status }\end{array}$ & "We have always lived with the thought that we were carriers." [Elizabeth] & $64 / 9$ \\
\hline \multirow[t]{2}{*}{$\begin{array}{l}\text { Difficulty changing risk } \\
\text { perception }\end{array}$} & $\begin{array}{l}\text { "I was not sure if I had the gene or not, but because of the [my] family history, I was } \\
\text { sure that my risk was more than the general population." [Louise] }\end{array}$ & $42 / 6$ \\
\hline & $\begin{array}{l}\text { "Exactly, it's like in my family, there has been so many people dying of cancer that are } \\
\text { not carriers. You can't just ignore that either, you know. Not having the gene is not a } \\
\text { big reassurance really. Like a really tiny reassurance." [Emma] }\end{array}$ & $51 / 3$ \\
\hline A lengthy process & $\begin{array}{l}\text { "I was expecting to be a carrier for so long that, suddenly not having it took me a } \\
\text { while." [Florence] }\end{array}$ & $49 / 3$ \\
\hline
\end{tabular}

Quotes are identified by fictitious names. 
invited to participate in one of the five focus groups. Seven women declined the invitation, mainly due to availability or distance issues, and the remaining 28 candidates were therefore assigned to one of the five groups. Each group included either five or six participants. The majority of participants (82\%) were French-speaking and $75 \%$ were younger than age 49 years when they had learned about their noncarrier status. More than 75\% of them had a university degree. Three participants (11\%) were of Ashkenazi Jewish origin. The women were from 31 to 71 years of age (mean $=45)$ and had been followed-up in primary care for a mean time of 4.9 years (range: $1.2-10.2$ years) by the time they completed the study.

Four main themes emerged from the analysis, and each of which is illustrated by relevant quotes (Tables 1 to 4 ).

Theme 1: becoming a noncarrier. Most participants felt relieved when they had learned that they did not carry the familial BRCA1/2 mutation. However, many of them also reported feelings of surprise and even disbelief toward their test result and, consequently, had difficulty casting off a longstanding self-identification as "a probable carrier." Participants often linked these reactions to their belonging to a family with a strong history of cancer. Even if they reported having been properly informed about their population-risk level, and even upon acknowledging it consciously, a number of participants still had trouble considering themselves at low risk for cancer. Many women reported still feeling unsafe and persisting in thinking about cancer because of their family history. Thus, for a number of noncarriers, accepting their new identity was experienced as a more or less protracted process.

Theme 2: a diversity of opinions about screening. Since their test result disclosure, all participants had been receiving primarycarefollow-up froma familydoctor $(n=26)$, gynecologist $(n=12)$, or both $(n=10)$. Some women also regularly consulted other specialists (e.g., oncologists, surgeons). The discussions revealed that the participants as well as their physicians expressed a variety of viewpoints regarding screening. While many women appreciated their doctor's openness to discuss screening matters, others mentioned not needing or wanting to engage in discussions on the subject and preferred to leave the decision up to their physician. Likewise, some physicians seemed to trust the ability of their patients to define their own needs and would rather let them make their own decisions and come back to consult them in case they needed screening.

Discussions about screening did not always lead to an agreement with the participants' doctors. Some women clearly stated their preference for more frequent screening than recommended or advised by their doctors. The women's hesitation or refusal to follow their physicians' suggestions to resort to less screening was often linked to anxiety associated with their familial history of cancer. When confronted with a woman's request for screening, especially if she expressed anxiety, clinicians tended to comply with their patient's demand.

In some other cases, physicians may have been reluctant to reduce or discontinue screening because they considered

Table 2 Relevant quotes for theme 2: a diversity of opinions about screening

\begin{tabular}{|c|c|c|}
\hline Selected subthemes & Quotes & $\begin{array}{l}\text { Age/years since } \\
\text { test disclosure }\end{array}$ \\
\hline \multirow[t]{2}{*}{$\begin{array}{l}\text { Preference to follow doctor's } \\
\text { advice }\end{array}$} & $\begin{array}{l}\text { "So I trust them. I don't decide. If they think I should do it, so I'm going to go do it. (...) } \\
\text { It's comforting. You know that you're followed." [Alice] }\end{array}$ & $47 / 8$ \\
\hline & $\begin{array}{l}\text { "Both my gynecologist and the specialist say that it's good for me to go every year. } \\
\text { They said: 'Because you're in a higher risk bracket'. So it's okay with me. "[Sarah] }\end{array}$ & $48 / 7$ \\
\hline $\begin{array}{l}\text { Confidence in patients' ability to } \\
\text { define their own needs }\end{array}$ & $\begin{array}{l}\text { "Since I've known that I do not have the gene, it's really depending on my own needs, } \\
\text { with my family doctor. If I feel something she prescribes a test but if not..." [Nadia] }\end{array}$ & $31 / 2$ \\
\hline $\begin{array}{l}\text { Preference of women for more } \\
\text { frequent screening }\end{array}$ & $\begin{array}{l}\text { "I remain vigilant. I want a mammogram every year, not every } 2 \text { years. I remain } \\
\text { vigilant, I do not want any surprises. (...) The fear persists." [Rose] }\end{array}$ & $55 / 7$ \\
\hline \multirow[t]{2}{*}{$\begin{array}{l}\text { Compliance of physicians with } \\
\text { patients' requests for more } \\
\text { screening }\end{array}$} & $\begin{array}{l}\text { "It stressed me a lot and I had panic attacks. It wasn't going well. She said: "Well, } \\
\text { I'll give you a test [probably rather a prescription] for a mammogram but it's just to } \\
\text { reassure you." [Claudia] }\end{array}$ & $41 / 6$ \\
\hline & "He said, "If you're worried, go have the test." That was it." [Olivia] & $62 / 4$ \\
\hline \multirow[t]{2}{*}{$\begin{array}{l}\text { Reluctance of physicians to } \\
\text { reduce or discontinue screening }\end{array}$} & $\begin{array}{l}\text { "My family doctor, when she found out that there was breast cancer in the family, she } \\
\text { suggested that I go for a mammogram. So, it was sort of comforting to do that (...) } \\
\text { because I knew that even if I was negative, going for a mammogram wouldn't be a } \\
\text { bad thing." [Nancy] }\end{array}$ & $47 / 8$ \\
\hline & $\begin{array}{l}\text { "In a way, he thinks it's better not to take any chances. That's his reaction. (...) It suits } \\
\text { me because it reassures me to do so." [Esther] }\end{array}$ & $38 / 2$ \\
\hline \multirow[t]{2}{*}{$\begin{array}{l}\text { Insistence of women to have less } \\
\text { screening }\end{array}$} & $\begin{array}{l}\text { "After it [the genetic test], I was relieved. I thought: Okay I don't have to do it } \\
\text { anymore. But then the doctor said: 'No, I still want you to come'." [Alice] }\end{array}$ & $47 / 8$ \\
\hline & $\begin{array}{l}\text { "She would have prescribed it [screening], but it was me who told her: 'Well, no. I } \\
\text { think there is no reason'." [Anne] }\end{array}$ & $40 / 6$ \\
\hline
\end{tabular}

Quotes are identified by fictitious names. 
Table 3 Relevant quotes for theme 3: diverse feelings towards medical follow-up

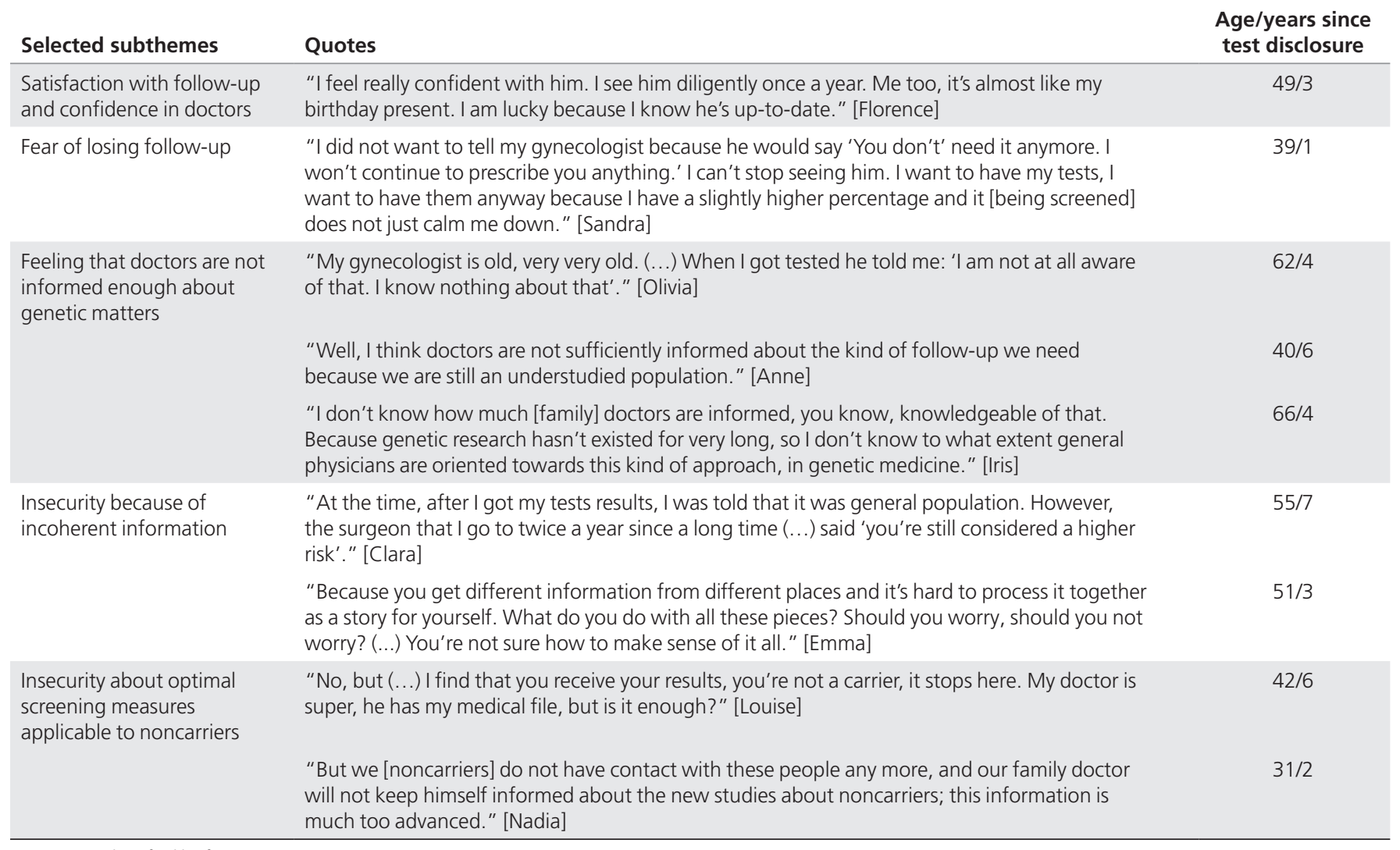

Quotes are identified by fictitious names.

their noncarrier patient to remain at a higher risk than the general population. Some participants valued such a cautious attitude from their physician, which was perceived as preventive and reassuring, even if it meant more screening. However, other participants reported cases where they were confronted with resistance to reduce or discontinue screening on their physician's part or had to insist to overcome this resistance.

Theme 3: diverse feelings toward medical follow-up. The majority of the participants were satisfied with their followup. They appreciated being able to trust their doctor and being in good hands. Many participants considered their primarycare follow-up as very important and could not envision its relinquishing. One woman even decided to hide her noncarrier status from her gynecologist for fear that he would stop providing follow-up.

Although a few participants particularly valued the competence of their physician to inform themselves, a larger number felt that their primary-care doctors were not knowledgeable enough regarding genetics and hereditary cancer issues and doubted their capacity to acquire such knowledge or to consider it as part of their expected training.

Other participants remained unsure about their cancer risk and the appropriate screening for them because they had received divergent or conflicting information from different physicians who do not share the same opinions or knowledge on these matters. These inconsistencies represented a source of worry for these participants who were questioning their doctor's capacity to provide them with optimal follow-up. In the same vein, a number of participants mentioned a feeling of being abandoned without any follow-up by the cancer genetic clinic because of their noncarrier status.

Theme 4: unmet information needs. The lack of information emerged as an important issue.

Many participants reported difficulties in remembering what they had been told upon test result disclosure due to the high emotional impact of this experience. Some of them mentioned a desire for having been provided with written information for future reference.

Comments were expressed about the difficulty to identify valid information among the existing and sometimes divergent data available on mutation status, cancer risk, and screening recommendations. The availability of clear and reliable scientific information was expressed as being particularly needed.

Many participants were aware of the continuing progress in genetics and worried about being left unaware of information that could impact their screening options. The need for information about the real cancer risk of noncarriers and for statistics on cancer rates among noncarriers were among the most frequently mentioned topics. 
Table 4 Relevant quotes for theme 4: unmet information needs

\begin{tabular}{|c|c|c|}
\hline Selected subthemes & Quotes & $\begin{array}{l}\text { Age/years } \\
\text { since test } \\
\text { disclosure }\end{array}$ \\
\hline \multirow[t]{2}{*}{$\begin{array}{l}\text { Need to retrieve or to be } \\
\text { re-explained the information } \\
\text { received at test disclosure }\end{array}$} & $\begin{array}{l}\text { "I think the stress is so high when you receive this kind of result. Even if the pressure drops, you } \\
\text { expected the worst. Now, the worst is not there, but you still wonder what you can do. Yes, } \\
\text { knowing the average, the chances and probabilities is OK, but you definitely do expect to have } \\
\text { some sort of a safety net." [Florence] }\end{array}$ & $49 / 3$ \\
\hline & $\begin{array}{l}\text { "What I would like to have is information on what is happening with these kinds of tests. When } \\
\text { we did it } 6 \text { or } 7 \text { years ago, I don't remember too much, it was new. It was really research, we } \\
\text { didn't know much. Since then we have received nothing." [Olivia] }\end{array}$ & $62 / 4$ \\
\hline \multirow[t]{2}{*}{$\begin{array}{l}\text { Difficulty to distinguish valid } \\
\text { information }\end{array}$} & $\begin{array}{l}\text { "Half of us have the impression that we're at the same risk as every other person on the street. } \\
\text { Some of us have the impression that we're still at higher risk... Because they're saying (...) that } \\
\text { you're at higher risk. So, who's right, you know?" [Emma] }\end{array}$ & $51 / 3$ \\
\hline & $\begin{array}{l}\text { "The real information, the good information. There is so much on the Internet. Sometimes we ask } \\
\text { ourselves 'Come on. Is it true or not? Who posted this information? Perhaps the information is } \\
\text { distorted. Is it up to date?' (...) The agencies should have the same information, the same sources. } \\
\text { At least the information would be good, it would be validated." [Eva] }\end{array}$ & $58 / 8$ \\
\hline $\begin{array}{l}\text { Awareness of evolving genetic } \\
\text { knowledge }\end{array}$ & $\begin{array}{l}\text { "Perhaps research will evolve, they will find that there are other, say, other interrelations. They } \\
\text { might have other recommendations for prevention. (...) There could be simple tests we do not } \\
\text { know about because we have not and will never be contacted again by the genetic side." [Laurie] }\end{array}$ & $46 / 10$ \\
\hline $\begin{array}{l}\text { Desire to participate in own } \\
\text { care }\end{array}$ & $\begin{array}{l}\text { "If we were current with the latest research they do, we would be able to monitor our state: What } \\
\text { I was told to do } 5 \text { years ago, is it still the right thing? We would be able to challenge our doctor } \\
\text { and be sure we receive the right follow-up." [Marylin] }\end{array}$ & $54 / 2$ \\
\hline \multirow{2}{*}{$\begin{array}{l}\text { Desire for contact or follow- } \\
\text { up opportunities with genetic } \\
\text { clinic }\end{array}$} & $\begin{array}{l}\text { "Maybe after 2-3 years: "How is it going? What is your follow-up?" To make sure that some type } \\
\text { of monitoring is being done even for noncarriers." [Louise] }\end{array}$ & $42 / 6$ \\
\hline & $\begin{array}{l}\text { "Me, I would really like to have a follow-up, after } 4 \text { years, } 5 \text { years, maybe? Is there research } \\
\text { being done somewhere on noncarriers who have developed other cancers, are we more at risk?" } \\
\text { [Charlotte] }\end{array}$ & $43 / 7$ \\
\hline
\end{tabular}

Quotes are identified by fictitious names.

Participants who felt poorly informed were insecure and worried about their care. Some of them noticed that being better informed with the most current data would empower them when discussing with their doctor, thus allowing them to participate actively in their own follow-up. In this regard, many suggestions concerned the possibility to recontact resource person(s) at the cancer genetic clinic to confirm the information provided at disclosure or to ask questions that had arisen since then. Other participants would have liked follow-up proposals (either in person or by telephone) whereby a cancer genetic team member would inquire about their well-being, validate that they received adequate primary-care follow-up, and provide them with any new information of interest.

Wishes for other, more general and accessible means of information were also expressed, both online and in print (pamphlets, guides, information sheets, or leaflets about scientific developments). Some participants also suggested more personalized communication tools (mailing lists, Internet chat, dedicated center/sites to facilitate interactions with specialized resources or other noncarriers to share stories or to attend useful information sessions). General lay information on noncarriers and related genetic topics was also mentioned as desirable by the participants, both for themselves and the general public.

\section{DISCUSSION}

This study was undertaken to learn more about how women who have not inherited a deleterious familial BRCA1/2 mutation acquire their noncarrier identity, and how this new awareness may impact their lives, particularly regarding screening-related issues.

For many participants, learning about their negative test result did not automatically result in their self-identification as a noncarrier. A number of them seemed to remain influenced by their familial history. They had difficulty viewing their cancer risk as average and persisted in having more or less pervasive worries about cancer. This is consistent with a study by Bakos et al., ${ }^{15}$ who observed that learning about the lack of inheritance of the familial mutation had not provided much reassurance to the women tested. This response was, in many cases, associated with having a strong family history of cancer. The prominent influence of a family history of cancer on risk perception has also previously been reported among members of families at risk for hereditary cancer. ${ }^{22-24}$ This seems to have also been the case in this study, although we could not verify if the risk perception was actually linked to the participants' familial history of cancer or whether the latter could somehow account for increased screening practices. Some participants 
who had grown up in such families might have developed a preconceived "probably at-risk" identity, which might have led them to engage in screening behaviors that may no longer be appropriate but nonetheless seem relatively resilient to change.

Approximately half of the participants still had screening practices that were somewhat higher than what would be expected given their near-population cancer risk and their age. Earlier research attempts to understand the reasons underlying such "excessive" screening behaviors among noncarriers so far have mainly focused on medical or psychosocial personal and familial characteristics of the noncarriers (e.g., family history of cancer, distress, anxiety, cancer worry, risk perception, selfvulnerability). ${ }^{11-14,25}$ However, our findings, which are based on group discussions, indicate that further factors might also be involved.

First, some participants reported difficulties with remembering or retrieving information related to their noncarrier status. Some of them mentioned that, years after their test result disclosure, they remained uncertain of their actual cancer risk and unsure about screening measures appropriate to their status. This is rather surprising because the majority of the participants reported having been adequately informed about risk and screening matters when they were counseled prior to genetic testing. However, a number of them mentioned that despite the good news, the emotional impact of the disclosure experience was such that they had forgotten whatever else they were told at this moment and even at the pretest consultation. Other participants felt that further information would be unavailable to them and that contact with the cancer genetic clinic would be limited. Furthermore, some of the women apparently did not or could not obtain such information from their primarycare physician, although these clinicians should have received a copy of the risk evaluation and screening recommendations regarding their noncarrier patients. Some women might conceivably have had personal motivations not to seek their personal information. Nevertheless, such difficulties in recalling or retrieving information regarding risk and screening might point out unexpected possible gaps in relaying the information between the genetic clinics, the primary-care doctors, or the noncarriers. Such informational gaps are unlikely to promote the transition of the noncarriers toward a lower risk perception and to modify their screening behaviors accordingly.

Second, the patient-physician interaction seems to have a determining influence on the screening behaviors of the participants. In many cases, screening decisions were made through more or less interactive discussions about screening between the participants and their physician. A range of viewpoints regarding screening were expressed from both physicians' and participants' perspectives. On the part of noncarriers, attitudes varied from passive compliance with the physician's recommendations to more assertive demands for increased screening or, less frequently, against screening. The physicians' positions varied from simple adherence to general population-based guidelines to more directive screening prescriptions. However, in many instances, discussions about screening seemed to result in prescriptions for somewhat more screening tests than what would be expected for noncarriers. This was particularly true when the physicians were confronted with screening-seeking by women expressing anxiety, in which case they tended to align their prescriptions with their patients' expectations. Patient factors such as anxiety and expectations have been shown to possibly influence physicians' decisions in prescribing screening tests to their patients. ${ }^{26}$ The physicians may be more vulnerable to this phenomenon when screening guidelines are unclear. ${ }^{27}$ With respect to true noncarriers, the source of uncertainty for the physicians might stem from recent controversial data suggesting that the actual cancer risk among true noncarriers from $B R C A 1 / 2$-positive families might be higher than in the general population. ${ }^{3,6,28-30}$ Our study suggests that a number of physicians may in some instances consider their noncarrier patients to be at higher than average risk, which is reflected in their screening prescriptions.

The situation of noncarriers is somewhat comparable to that of women found to be ineligible for genetic testing for breast cancer risk, as described by Bottorff et al..$^{31}$ In that study, women referred to their experience as "falling through the cracks" and reported frustration because of having been left without adequate information and support. Some participants in our study might have experienced a similar "ineligibility" sensation because being declared as a noncarrier resulted in their "exclusion" from genetic follow-up and in unmet information needs. However, primary-care follow-up was generally highly valued and felt to be essential by most participants. Being taken care of, even if not by specialized health resources, seemed to have an important comforting effect for several women, among whom many remained anxious about cancer or did not derive much reassurance from their negative test result. The emotional investment of the participants with their primary-care doctors may stem from a feeling of abandonment that was expressed by some participants relative to their exclusion from further genetic follow-up. Our study suggests that the extent of the disappointment felt by some true noncarriers upon disclosure of their test result and exclusion from further genetic follow-up might have been somewhat unnoticed. Special attention should be given to such reactions because they may have deterrent effects to the point of perhaps discouraging some participants from seeking information or help about their future care.

Information gaps emerged as a major issue in this study. A number of participants were uncertain about the information received at the test disclosure being current relative to risk and screening and feared possibly being unaware of updated information that may be pertinent to their own risk management. Statistics on breast and ovarian cancer rates among noncarriers were also mentioned as being particularly needed. Many participants reported actively seeking information on their own and are therefore aware of the constant progress of genetics. Paradoxically, however, this approach was confusing for some women who expressed a strong desire for reliable scientific information on noncarrier cancer risks and other relevant genetic issues. These gaps in information clearly highlight the 
necessity of finding better or new ways not only to ensure that noncarriers are provided with adequate information but also to keep them informed in a timely fashion and according to their particular status. This is especially important because this study pointed to several instances when women could not rely on their primary-care doctors for information because they felt or feared that genetic issues are beyond their capabilities or responsibilities. This further brings attention to emerging new realities that may affect the physicians' roles or impact on the health-care system, as new information pathways or resources might need to be developed.

Factors that limit the scope of our findings should be kept in mind. First, the time since the participants had been informed about their genetic test result may represent a limitation because our findings are solely based on the participants' account of the facts. Memory bias can influence the participants' recollection, e.g., what they recall from the physician's actual recommendations at the time of the consultation. However, the participants were able to comment on a reality that was often already familiar to them at the time of the study, which confers a unique asset to this research compared with earlier studies with noncarriers. Second, the lack of information regarding the participants' family history might impose a further limitation because such information might account for a participant's unique needs or preferences pertinent to her screening behavior. Although some participants spontaneously mentioned aspects of their familial history at the sessions, our discussion guide, unfortunately, did not include specific questions about this topic. Therefore, cancer risk perceptions or screening practices of the participants could not be correlated with their family history. Third, although the number of participants was relatively small, it was nonetheless sufficient to meet the objectives of the study. We selected a purposive sample of participants to obtain a wider range of viewpoints by including women of different ages and screening experiences. Care was also taken to ensure satisfactory diversity among participants with respect to their sociocultural background and recruitment setting. The fact that all focus groups were moderated by the same person, in both French and English, optimized the intergroup uniformity of the animation and, therefore, the quality of the data.

Our findings suggest that true noncarriers have specific needs. As already stated by Bakos et al. (2008), "Being a truenegative member of a mutation-positive family is more complex than previously described." ${ }^{\prime 5}$ In particular, noncarriers may no longer be defined merely as a group of people with a cancer risk comparable to that of women of the general population. The difficulty experienced by some women to adopt a noncarrier identity may reflect their increasing awareness that their cancer risk is determined by individual risk characteristics and that this will probably require more individualized risk-management choices. In this regard, polygenic risk models that capture the combined effects of multiple single-nucleotide polymorphisms are currently undergoing development. Nearly 100 established single-nucleotide polymorphisms are associated with breast cancer risk ${ }^{32}$ in addition to high-risk mutations in the BRCA1 and BRCA2 genes. Recent studies ${ }^{33,34}$ suggest that such risk models, when combined with other risk factors, might help to refine cancer risk estimations in these women in the future and to inform targeted screening and prevention strategies.

Participants in this study were very proactive in suggesting means to overcome what they clearly expressed as a need for improved access to and updating of information regarding their own cancer risk and regarding the screening appropriate to their status. This suggests that a majority of women have a real desire to actively participate in their own care and should be considered as a very positive asset in the future efforts to develop services for that population.

\section{SUPPLEMENTARY MATERIAL}

Supplementary material is linked to the online version of the paper at http://www.nature.com/gim

\section{ACKNOWLEDGMENTS}

This study was funded by the Quebec Breast Cancer Foundation (QBCF). We are grateful to Claudia Côté, Stéphanie Côté, and Rachel Silva-Smith for their assistance in recruiting the participants. We also thank Maude Lafleur (SOM, Research \& Surveys) for moderating the groups and writing the summary report and Richard Poulin for revising the manuscript. Finally, we express our thanks to all study participants for devoting their time to this project.

\section{DISCLOSURE}

J.S. is chair holder of the Canada Research Chair in Oncogenetics. The authors declare no conflict of interest.

\section{REFERENCES}

1. Antoniou A, Pharoah PD, Narod S, et al. Average risks of breast and ovarian cancer associated with BRCA1 or BRCA2 mutations detected in case series unselected for family history: a combined analysis of 22 studies. Am J Hum Genet 2003;72:1117-1130

2. Eisinger $F$, Bressac $B, C$ astaigne $D$, et al. [Identification and management of hereditary predisposition to cancer of the breast and the ovary (update 2004)]. Bull Cancer 2004;91:219-237

3. Domchek SM, Gaudet MM, Stopfer JE, et al. Breast cancer risks in individuals testing negative for a known family mutation in BRCA1 or BRCA2. Breast Cancer Res Treat 2010;119:409-414.

4. National Institute for Health and Care Excellence (NICE). Familial breast cancer. Classification and care of people at risk of familial breast cancer and management of breast cancer and related risks in people with a family history of breast cancer. NICE Clinical Guideline 164. 2013.

5. Berliner JL, Fay AM; Practice Issues Subcommittee of the National Society of Genetic Counselors' Familial Cancer Risk Counseling Special Interest Group. Risk assessment and genetic counseling for hereditary breast and ovarian cancer: recommendations of the National Society of Genetic Counselors. J Genet Couns 2007;16:241-260.

6. Harvey SL, Milne RL, McLachlan SA, et al.; kConFab Investigators. Prospective study of breast cancer risk for mutation negative women from BRCA1 or BRCA2 mutation positive families. Breast Cancer Res Treat 2011;130:1057-1061.

7. Tonelli M, Gorber SC, Joffres M, et al. Recommendations on screening for breast cancer in average-risk women aged 40-74 years. CMAJ 2011;183:1991-2001.

8. Morrison B. Screening for Breast Cancer. Canadian Task Force on the Periodic Health Examination Canadian Guide to Clinical Preventive Health Care. Health Canada: Ottawa, 1994:788-795.

9. Ringash J; Canadian Task Force on Preventive Health Care. Preventive health care, 2001 update: screening mammography among women aged $40-49$ years at average risk of breast cancer. CMAJ 2001;164:469-476. 


\section{ORIGINAL RESEARCH ARTICLE}

10. US Preventive Services Task Force. Screening for breast cancer: U.S. Preventive Services Task Force recommendation statement. Ann Intern Med 2009;151:716-726, W-236.

11. Dorval $M$, Noguès $C$, Berthet $P$, et al.; INHERIT BRCAs; GENEPSO Cohort. Breast and ovarian cancer screening of non-carriers from BRCA1/2 mutation-positive families: 2-year follow-up of cohorts from France and Quebec. Eur J Hum Genet 2011;19:494-499.

12. Dawson SJ, Price MA, Jenkins MA, et al. Cancer risk management practices of noncarriers within BRCA1/2 mutation positive families in the Kathleen Cuningham Foundation Consortium for Research into Familial Breast Cancer. J Clin Oncol 2008;26:225-232.

13. Duprez C, Christophe V, Milhabet I, et al. Comparison of the screening practices of unaffected noncarriers under 40 and between 40 and 49 in BRCA1/2 families. J Genet Couns 2013;22:469-481.

14. Milhabet I, Duprez C, Krzeminski A, Christophe V. Cancer risk comparative perception and overscreening behaviours of non-carriers from BRCA1/2 families. Eur J Cancer Care (Engl) 2013;22:540-548.

15. Bakos AD, Hutson SP, Loud JT, Peters JA, Giusti RM, Greene MH. BRCA mutation-negative women from hereditary breast and ovarian cancer families: a qualitative study of the BRCA-negative experience. Health Expect 2008; 11:220-231.

16. Macrae L, de Souza AN, Loiselle CG, Wong N. Experience of BRCA1/2 mutationnegative young women from families with hereditary breast and ovarian cancer: a qualitative study. Hered Cancer Clin Pract 2013:11:14

17. Krueger R, Casey M. Focus Groups: A Practical Guide for Applied Research. 4th edn. SAGE: Thousand Oaks, CA, 2009

18. Mays N, Pope C. Rigour and qualitative research. BMJ 1995;311:109-112.

19. Malterud K. Qualitative research: standards, challenges, and guidelines. Lancet 2001;358:483-488

20. Boyatzis R. Transforming Qualitative Information: Thematic Analysis and Code Development. SAGE Publications: Thousand Oaks, CA, 1998.

21. QSR International Pty Ltd. NVivo Qualitative Data Analysis Software. 8th edn. 2008.

22. d'Agincourt-Canning L. A gift or a yoke? Women's and men's responses to genetic risk information from BRCA1 and BRCA2 testing. Clin Genet 2006;70:462-472.
23. Hilgart J, Phelps C, Bennett P, Hood K, Brain K, Murray A. "I have always believed I was at high risk." The role of expectation in emotional responses to the receipt of an average, moderate or high cancer genetic risk assessment result: a thematic analysis of free-text questionnaire comments. Fam Cancer 2010;9:469-477.

24. d'Agincourt-Canning L. The effect of experiential knowledge on construction of risk perception in hereditary breast/ovarian cancer. J Genet Couns 2005;14: 55-69.

25. Foster C, Watson M, Eeles R, et al.; Psychosocial Study Collaborators. Predictive genetic testing for BRCA1/2 in a UK clinical cohort: three-year follow-up. Br J Cancer 2007;96:718-724.

26. Haggerty J, Tudiver F, Brown JB, Herbert C, Ciampi A, Guibert R. Patients' anxiety and expectations: how they influence family physicians' decisions to order cancer screening tests. Can Fam Physician 2005;51:1658-1659.

27. Tudiver F, Brown JB, Medved W, et al. Making decisions about cancer screening when the guidelines are unclear or conflicting. J Fam Pract 2001;50: 682-687.

28. Kurian AW, Gong GD, John EM, et al. Breast cancer risk for noncarriers of family-specific BRCA1 and BRCA2 mutations: findings from the Breast Cancer Family Registry. J Clin Oncol 2011;29:4505-4509.

29. Evans DG, Howell A. Breast cancer risk for noncarriers of family-specific BRCA1 and BRCA2 mutations: more trouble with phenocopies. J Clin Oncol 2012;30:1142-3; author reply 1143.

30. Bernholtz S, Laitman Y, Kaufman B, Shimon-Paluch S, Friedman E. Phenocopy breast cancer rates in Israeli BRCA1 BRCA2 mutation carrier families: is the risk increased in non-carriers? Breast Cancer Res Treat 2012;132:669-673.

31. Bottorff JL, Balneaves LG, Buxton J, et al. Falling through the cracks. Women's experiences of ineligibility for genetic testing for risk of breast cancer. Can Fam Physician 2000;46:1449-1456.

32. Fachal L, Dunning AM. From candidate gene studies to GWAS and post-GWAS analyses in breast cancer. Curr Opin Genet Dev 2015;30:32-41.

33. Mavaddat N, Pharoah PD, Michailidou K, et al. Prediction of breast cancer risk based on profiling with common genetic variants. J Natl Cancer Inst 2015;107.

34. Garcia-Closas M, Gunsoy NB, Chatterjee N. Combined associations of genetic and environmental risk factors: implications for prevention of breast cancer. J Natl Cancer Inst 2014:106 